\title{
Inclusão de surdos: revisão integrativa da literatura científica
}

\author{
Roberta Espote - Universidade Federal do Triângulo Mineiro, Uberaba, Minas Gerais, Brasil \\ Conceição Aparecida Serralha - Universidade Federal do Triângulo Mineiro, Uberaba, Minas Gerais, Brasil \\ Fabio Scorsolini-Comin - Universidade Federal do Triângulo Mineiro, Uberaba, Minas Gerais, Brasil
}

\begin{abstract}
Resumo
O objetivo foi realizar uma revisão integrativa da literatura científica nacional sobre a inclusão de surdos. A partir de buscas nas bases LILACS, PePSIC e SciELO, entre 2005 e 2011, foram recuperados e analisados na íntegra sete artigos. Nota-se que, apesar dos esforços, a inclusão dos surdos em ambientes escolares não tem ocorrido de maneira satisfatória, havendo despreparo dos educadores e também dos sistemas de ensino. Predominam visões reducionistas que priorizam a oferta de vagas e recursos físicos como elementos únicos para a inclusão, desconsiderando abordagens que abarquem seus protagonistas, familiares, profissionais de saúde e de educação de maneira integrada. É necessário que a discussão sobre a inclusão de surdos não se restrinja a ambientes educacionais.

Palavras-chave: Deficientes auditivos, Surdos, Inclusão, Escola.
\end{abstract}

\section{Inclusion of the deaf: an integrative review of scientific literature}

\begin{abstract}
The aim was to conduct an integrative review of national scientific literature on the inclusion of the deaf. Through searches of the LILACS, SciELO and PePSIC between 2005 and 2011 seven articles were retrieved and analyzed. It can be noticed that, despite the efforts, the inclusion of deaf people in school settings has not occurred satisfactorily, with unprepared educators. The predominant reductionist views that prioritize the supply of places and physical resources such as unique elements for inclusion, disregarding approaches that cover its protagonists, family, health and education professionals. It is necessary that the discussion on the inclusion of deaf people not be limited to educational environments.

Keywords: Deaf, Inclusion, Schoool.
\end{abstract}

Inclusión de sordos: revisión integrada de la literatura científica

\begin{abstract}
Resumen
El objetivo de este estudio fue realizar una revisión integrada de la literatura científica nacional sobre la inclusión de sordos. A partir de las búsquedas en las bases LILACS, PePSIC y SciELO, de 2005 y 2011, fueron recuperados y analizados integralmente siete artículos. Se nota que, a pesar de los esfuerzos, la inclusión de los sordos en los ambientes escolares no viene ocurriendo de manera satisfactoria, hay despreparación de los educadores y también de los sistemas de enseñanza. Predominan visiones reduccionistas que priorizan la necesidad de plazas y recursos físicos adaptados como elementos únicos para la inclusión, desconsiderando abordajes que abarquen sus protagonistas, familiares, profesionales de la salud y de educación de manera integrada. Es necesario que la discusión sobre la inclusión de sordos no se limite a los ambientes educacionales.

Palabras clave: Deficientes auditivos, Sordos, Inclusión, Escuela.
\end{abstract}

A questão da inclusão e exclusão social é vista por muitos autores como uma dialética, ou seja, inclusão e exclusão não são termos antagônicos, necessariamente, e sim complementares, já que um depende do outro para existir (Carreteiro, 1999; Chammé, 2002; Diogo \& Coutinho, 2006; Sawaia, 1999;). Para Sposati (2002), são os valores presentes nas relações sociais que definem quem será incluído e quem será excluído, uma vez que são essas relações sociais que criam estereótipos e preconceitos que alimentam a discriminação. Sendo assim, a exclusão pode ser uma forma de se efetivar a discriminação. Por muito tempo, pensar em exclusão levava à ideia de que esta deveria ser combatida, como algo que atrapalha a questão social. Porém, para Sawaia (1999), a exclusão não seria uma falha do sistema e sim aquilo que o mantém em funcionamento, e é nisto que consiste a dialética exclusão e inclusão: os excluídos fazem parte da sociedade ajudando a manter a ordem social.

Disponivel em www.scielo.br
Outra confusão recorrente é pensar a exclusão como única forma de participação do indivíduo no mundo, como se um indivíduo que é excluído só pudesse usar dessa representação. O fato é que uma pessoa nunca é totalmente excluída, de acordo com Carreteiro (1999), pois "há sempre algum tipo de inserção ou de afiliação do sujeito individual ou coletivo, no interior de certas categorias e sistemas sociais" (p. 87), ou seja, de alguma forma o excluído se encontra incluído, nem que seja no grupo dos excluídos. É importante ressaltar que a exclusão é um fenômeno social e não pode ser vista, de forma alguma, como uma atitude deliberada do próprio indivíduo. Assim, para Sposati (2002), não é possível excluir-se a si mesmo; é excluído aquele que gostaria de estar incluído e por uma decisão que não a sua, acaba por não ser incluído.

A partir desse ponto de vista, então, quem seriam os excluídos? Excluídos são todos aqueles que, de 
alguma forma se encontram impedidos de participar da maioria - não no sentido quantitativo da palavra - que está intimamente ligada ao poder, ao ideal a ser alcançado (Roso, Strey, Guareschi, \& Bueno, 2002). Falar de exclusão implica necessariamente falar de preconceito, sendo este, na maior parte das vezes, alimentado por estereótipos que são criados socialmente. No caso do preconceito contra qualquer tipo de deficiência, mais do que uma questão cultural, encontra-se uma questão de fantasias quanto a deficiência apresentada, sendo a maioria delas relacionadas com a ideia de falta de capacidade do indivíduo deficiente.

\section{Os surdos e a dialética inclusão/ exclusão}

Baptista (2009), retomando as ideias de Foucault (1986, 2001), busca uma relação entre a exclusão do louco e do deficiente, afirmando que em ambos os casos há quatro sistemas de exclusão: trabalho, família, palavra e jogo. Ao fazer essa comparação, fica a ideia de que, sendo excluído de todos esses âmbitos, não sobram muitas alternativas de inclusão para os deficientes. Dentro desse grupo, podemos encontrar mais especificamente os surdos. Os próprios termos deficiente auditivo e surdo-mudo são estereótipos carregados de preconceito e, ao contrário do que se imagina, os indivíduos que não possuem capacidade de audição preferem ser reconhecidos como surdos a serem reconhecidos como deficientes auditivos. Isso se deve ao fato de a palavra deficiente já ter se tornado pejorativa. Ser chamado de surdo-mudo também é motivo de desagrado, uma vez que os surdos não são necessariamente mudos. Salvo exceções, os surdos possuem o aparelho fonador com total capacidade de uso (Gesser, 2008).

No caso dos surdos, há uma grande dificuldade na fluência da comunicação, o que exige que o outro esteja disposto a tentar entendê-lo. Os surdos apresentam uma maneira típica de comunicação que na ausência da fala é repleta de gestos e ruídos, podendo causar estranhamento. E esse estranhamento pode ser o início de uma discriminação, já que, não tão raro, a pessoa passaria a ignorá-lo evitando a situação sentida como estranha e que pode gerar constrangimento pela própria pessoa não saber como se comunicar (Franco, 2009; Ribeiro, 2011; Souza, 2011).

Sabe-se que, antigamente, a exclusão de pessoas surdas era ainda maior. Não lhes era permitido que ingressassem no mercado de trabalho e isso se devia tanto a uma falta de preparo dos surdos quanto da empresa. Com o passar do tempo foram ocorrendo muitas mudanças sociais que levaram à criação de leis que regulamentam, por exemplo, a abertura de vagas para deficientes em concursos públicos, processos seletivos e empresas do terceiro setor (Borges, Bello, Leite, \& Araujo, 2002; Tanaka \& Manzini, 2005), levando à necessidade de que se discuta o acesso dessas pessoas ao conhecimento e a treinamentos que a incluam no mercado profissional, por exemplo.

\section{Os surdos e sua inclusão em ambientes escolares}

Atualmente, inclusão é a palavra de ordem no âmbito da escola. Até um tempo atrás, somente a existência de escolas especiais, destinadas a deficientes, bastava para que se acreditasse na igualdade de oportunidades entre deficientes e pessoas ditas normais. Com o entendimento de que frequentar escolas especiais não significa inclusão, pelo contrário, reforça ainda mais a exclusão, no sentido de delimitar o espaço destinado aos deficientes, e com a comprovação de que a evolução da criança deficiente é ainda maior quando, além de frequentar a escola especial, frequenta em outro período uma escola regular, houve um intenso trabalho para incluir deficientes no ambiente escolar regular (Baptista, 2009; Melo \& Ferreira, 2009; Monteiro \& Manzini, 2008; Scorsolini-Comin \& Amorim, 2010; Souza, 2011; Takase \& Chun, 2010; Zortéa, 2007). A educação inclusiva já vinha sendo considerada na legislação brasileira (Constituição de 1988), mas foi introduzida mais explicitamente nas políticas públicas do sistema educacional brasileiro por meio de diferentes leis e diretrizes. Entre estas, cita-se a Política Nacional de Educação Especial (Brasil, 1994), a Lei de Diretrizes e Bases da Educação Nacional (Brasil, 1996) e o Parâmetro Curricular Nacional (PCN) - Adaptações Curriculares para a Educação de Alunos com Necessidades Educacionais Especiais.

Com isso, várias questões relacionadas à surdez passaram a ser consideradas. A primeira delas é que a deficiência auditiva não pode ser entendida de forma individual. Muito se conhece sobre a relação surdez e debilidade na fala, porém, não é só a fala que sofre interferência da falta de audição. Os processos de leitura e escrita também podem sofrer, já que estes também se relacionam com a fala e com a audição. Isso faz com que crianças surdas fiquem atrasadas em seu desenvolvimento intelectual, ao passo que uma criança ouvinte, no momento de aprender a escrever, já possui um arsenal de palavras que sabe falar e dos quais entende o significado. As crianças surdas não possuem esse arsenal, o que vai exigir da escola e dos professores, mais preparo para lidar com elas, sendo necessárias outras estratégias para ensiná-las (Duarte \& Brazorotto, 2009). De acordo com Manente, Rodrigues e Palamin (2007), um aluno irá precisar de maior atenção por parte do educador, quando ele não conseguir acompanhar a aprendizagem de seu grupo de igual idade cronológica. Dentre os fatores que 
influenciam a não-aprendizagem, podem ser encontrados o espaço local, a estrutura curricular ou as metodologias inadequadas.

O fato de a inclusão escolar ser atualmente um assunto amplamente discutido não significa que as pessoas que a debatem entendam a inclusão da mesma maneira. Apesar de todos os estudos e conhecimentos já alcançados, há ainda uma tendência, que Baptista (2009) chama de cisão entre os fenômenos: as pessoas ainda veem o outro como sendo diferente de si, e nesse caso, como sendo menos, e essa atitude entre os próprios profissionais perpetua todos os mitos que impedem uma inclusão de fato. Atualmente, segundo esse autor, é possível ouvir vários relatos de alunos que são "jogados" dentro das salas de aula de ensino regular, sendo que não houve para isso nenhum preparo do professor e nenhuma mudança física no ambiente com adição de novos métodos de ensino, capazes de atender às necessidades dessas crianças. A consequência desse movimento são as "falsas" inclusões ou mesmo inclusões perversas (Sawaia, 1999). Ocorre, por um lado, uma tendência à técnica, que define com quais intervenções determinados indivíduos poderão se beneficiar (Baptista, 2009) e, por outro, falta de tato ao lidar com esses indivíduos, buscando uma massificação tão comum e condizente com a nossa realidade social atual.

Muito se fala sobre inclusão na escola fundamental e no ensino médio, e se vê que nesse processo ainda há muito que se aprimorar, ao se tratar da inclusão no ensino superior, a situação é ainda mais precária (Bortoleto, Rodrigues, \& Palamin, 2002; Manente e cols., 2007). Mesmo com todas as limitações, têm ocorrido muitos avanços nessa área. Contudo, não se pode entender que apenas a criação de leis seja eficaz para promover as mudanças necessárias. O principal ponto a ser modificado é a visão simplificadora que se tem de todo o processo. Desse modo, devem ser considerados os alunos com suas limitações e suas capacidades muitas vezes não completamente exploradas, a família desses alunos, professores envolvidos (preparação, visão de inclusão, comprometimento), escolas nas quais ocorre a inclusão (recursos, visão de inclusão, apoio, inovação), profissionais de saúde e poder público (Baptista, 2009; Roriz, Amorim, \& Rossetti-Ferreira, 2010; RossettiFerreira \& Solon, 2010; Souza, 2011).

Posto isso, este estudo objetiva apresentar uma revisão integrativa da literatura científica nacional sobre a inclusão de surdos, buscando avaliar como esse processo tem ocorrido em ambientes educacionais.
Tipo de estudo

Este estudo caracteriza-se como uma revisão integrativa da literatura científica. Esse tipo de estudo objetiva, por meio de uma metodologia sistemática de busca, seleção e análise, descrever a produção científica acerca de uma temática, destacando o estado da arte e apresentando as possibilidades de futuras investigações. Proporciona uma leitura crítica da literatura científica, na qual são identificados e selecionados estudos com rigor e método científico, com o propósito de analisálos para que se possa delinear um perfil dos trabalhos publicados, contribuindo para a discussão acerca dos resultados de pesquisa e para o desenvolvimento de estudos futuros (Creswell, 2010).

\section{Bases indexadoras}

Este estudo envolveu uma busca sistemática nos seguintes indexadores eletrônicos: LILACS, SciELO e PePSIC. Os descritores utilizados foram: "deficiente auditivo" e "inclusão", "deficientes auditivos" e "inclusão", "surdo" e "inclusão" e "surdos" e "inclusão".

\section{Critérios de inclusão}

(1) artigos indexados; (2) redigidos no idioma português; (3) publicados no período de janeiro de 2005 a dezembro de 2011; (4) com temática pertinente ao objetivo da revisão. A seleção apenas de artigos indexados visou a cotejar produções que passam, necessariamente, por um processo de avaliação por pares, com rigoroso controle de qualidade. A adoção desse critério baseou-se em outras revisões, com semelhante grau de rigor, que indicaram a necessidade de se tomar esse cuidado como balizador de uma condição de produção em dado período (ScorsoliniComin \& Santos, 2010). A seleção de artigos publicados entre 2005 e 2011 visou a abarcar apenas publicações recentes, a fim de traçar um retrato mais fiel da produção contemporânea, bem como apontar possíveis lacunas e aberturas para novos estudos. Não foram feitas restrições em relação ao tipo de delineamento metodológico (estudos teóricos, empíricos, de revisão, estudos de caso ou outros), nem em relação às abordagens teóricas ou às áreas nas quais as pesquisas foram desenvolvidas.

\section{Critérios de exclusão}

(1) livros, capítulos de livro, resenhas, cartas, notícias, dissertações e teses; (2) temática distante do objetivo do trabalho; (3) artigos publicados antes de 2005. Como exemplo de publicações muito distantes do tema investigado, podem ser mencionados estudos 
que traziam apenas tangencialmente a questão da surdez, discutindo apenas a inclusão.

\section{Procedimento}

O levantamento bibliográfico ocorreu em janeiro de 2012. Em um primeiro momento, foi realizada uma leitura minuciosa dos resumos encontrados a partir dos unitermos utilizados e da combinação dos mesmos, excluindo-se os trabalhos que não se enquadravam nos critérios de inclusão elencados. Após uma primeira seleção realizada pelo exame dos resumos, os estudos selecionados foram recuperados, examinados e lidos na íntegra. Posteriormente, em função da maior ou menor proximidade com o tema de interesse, uma nova seleção foi realizada, restringindo-se a revisão apenas aos artigos diretamente relacionados à inclusão de surdos no ambiente escolar. Foram incorporadas à revisão apenas as publicações recuperadas nessa última seleção, que constituíram o corpus de análise do presente estudo.

Foram encontrados 57 resumos que correspondiam à somatória de todas as buscas realizadas, seja com os descritores tomados isoladamente ,seja a partir de suas combinações, nas três bases indexadoras utilizadas para este estudo. Posteriormente, segundo os critérios de inclusão/exclusão adotados e levando-se em consideração as combinações de descritores, a maior parte desse montante foi descartada por não ser condizente com o assunto ou por tratar da temática apenas tangencialmente. Estudos encontrados em mais de uma base indexadora foram computados uma única vez. Considerando o exposto, foram selecionados, recuperados e analisados na íntegra os artigos que, após merecerem análise criteriosa, foram categorizados. Essa categorização favoreceu a reflexão crítica sobre as dimensões cruciais que caracterizam o estado da arte sobre a temática.

\section{Resultados e Discussão}

A Tabela 1 apresenta a quantidade de trabalhos encontrados, selecionados com base na leitura dos resumos e recuperados a partir da leitura dos textos completos. Como se pode notar, dos 57 trabalhos encontrados inicialmente, após a aplicação dos critérios de inclusão e exclusão, sete destes foram recuperados e analisados na íntegra.

A Tabela 2 sumariza os trabalhos recuperados $(n=7)$ em termos dos títulos dos artigos, autores, instituição de origem dos autores e ano de publicação.

Tabela 1. Número de trabalhos encontrados, selecionados e recuperados nas bases indexadoras

\begin{tabular}{lccccccccc}
\hline Descritores & \multicolumn{3}{c}{ Encontrados } & \multicolumn{3}{c}{ Selecionados } & \multicolumn{3}{c}{ Recuperados } \\
\cline { 2 - 10 } & LILACS & PePSIC & SciELO & LILACS & PePSIC & SciELO & LILACS & PePSIC & SciELO \\
\hline $\begin{array}{l}\text { Deficiente auditivo e } \\
\text { inclusão }\end{array}$ & 4 & 0 & 2 & 2 & 0 & 1 & 2 & 0 & 1 \\
$\begin{array}{l}\text { Deficientes Auditivo } \\
\text { e inclusão }\end{array}$ & 6 & 0 & 5 & 4 & 0 & 3 & 0 & 0 & 1 \\
$\begin{array}{l}\text { Surdo e inclusão } \\
\text { Surdos e inclusão }\end{array}$ & 10 & 0 & 7 & 4 & 0 & 3 & 1 & 0 & 1 \\
\hline Total & 12 & 0 & 11 & 4 & 0 & 5 & 0 & 0 & 1 \\
\hline
\end{tabular}

Tabela 2. Identificação dos estudos recuperados em termos de título, autores e ano de publicação (n=7)

\begin{tabular}{|c|c|c|c|c|}
\hline $\mathrm{N}^{\circ}$ & Ano & Título & Autores & Instituição de origem \\
\hline 1 & 2006 & $\begin{array}{l}\text { A inserção do aluno surdo no ensino regular: visão } \\
\text { de um grupo de professores do estado do Paraná }\end{array}$ & $\begin{array}{l}\text { Guarinello, Berberian, } \\
\text { Santana, Massi, Paula }\end{array}$ & Univ. Tuiuti do Paraná \\
\hline 2 & 2007 & $\begin{array}{l}\text { O que dizem/sentem alunos participantes de uma } \\
\text { experiência de inclusão escolar com aluno surdo }\end{array}$ & Lacerda & $\begin{array}{l}\text { Univ.Metodista de } \\
\text { Piracicaba }\end{array}$ \\
\hline 3 & 2008 & $\begin{array}{l}\text { A dramatização como estratégia de aprendizagem } \\
\text { da linguagem Escrita para o deficiente auditivo }\end{array}$ & Pinotti, Boscolo & Univ. de Araraquara \\
\hline 4 & 2009 & $\begin{array}{l}\text { O processo de inclusão de crianças com deficiência } \\
\text { auditiva na escola regular: vivências de professores }\end{array}$ & Rios, Novaes & $\begin{array}{l}\text { Pontifícia Universidade } \\
\text { Católica de São Paulo }\end{array}$ \\
\hline 5 & 2009 & $\begin{array}{l}\text { A inclusão do aluno com perda auditiva na rede } \\
\text { municipal de ensino da cidade de Marília }\end{array}$ & Seno & $\begin{array}{l}\text { Secretaria Municipal da } \\
\text { Educação de Marília-SP }\end{array}$ \\
\hline 6 & 2010 & $\begin{array}{l}\text { Estudantes surdos no ensino superior: reflexões } \\
\text { sobre a inclusão }\end{array}$ & $\begin{array}{l}\text { Bisol, Valentini, } \\
\text { Simioni, Zanchin }\end{array}$ & Univ. de Caxias do Sul \\
\hline 7 & 2010 & $\begin{array}{l}\text { Conhecimentos de professores sobre perda auditiva } \\
\text { e suas atitudes frente à inclusão }\end{array}$ & $\begin{array}{l}\text { Delgado-Pinheiro, } \\
\text { Omote }\end{array}$ & $\begin{array}{l}\text { Univ. Estadual Paulista } \\
\text { "Júlio de Mesquita Fo" }\end{array}$ \\
\hline
\end{tabular}


Dos trabalhos recuperados dentro do período estabelecido de 2005 a 2011, não houve nenhum trabalho do ano de 2005. Os anos de 2006, 2007 e 2008 tiveram um registro cada e os de 2009 e 2010 tiveram dois registros cada. Esses dados indicam que houve certa linearidade na produção de trabalhos referente ao tema de inclusão de deficientes auditivos no ambiente escolar, no período consultado. Também foi analisada a formação do primeiro autor de cada trabalho: dos sete estudos, todos são do sexo feminino e seis são fonoaudiólogas, sendo apenas uma psicóloga. De acordo com Margall e cols. (2006), é possível perceber que a deficiência auditiva vai além de um fator puramente médico, envolvendo uma multiplicidade de fatores que exigem a atuação de vários profissionais, e apesar de todas as complicações referentes ao processo de inclusão dos deficientes auditivos, toda a subjetividade envolvida e todo o sofrimento psíquico existente, a psicologia não tem se ocupado desse tema, e se o tem feito, não há publicações suficientes para contribuir com a difusão do conhecimento dessa prática profissional.

A constatação de uma atuação quase exclusiva da Fonoaudiologia pode se dever ao fato de que a principal e mais básica necessidade do deficiente auditivo é a de comunicação. Já que nem todo surdo é mudo e que questões da fala são específicas da fonoaudiologia, esta é chamada para atuar primeiramente. Isso também mostra que, por vezes, questões psicológicas são colocadas em segundo plano. Com relação à origem institucional dos trabalhos produzidos, apenas um deles não apresentou ligação com nenhuma instituição de ensino superior, e dos outros seis, cinco foram filiados a instituições de ensino superior privadas duas universidades do Estado de São Paulo, uma do Paraná e uma do Rio Grande do Sul. Uma das pesquisas ocorreu filiada a uma instituição de ensino superior pública de São Paulo, ficando evidente que o tema abordado em sua especificidade não apresenta grande interesse em todo o território nacional. Isso é ainda confirmado pelo fato de quatro dos artigos terem sido publicados na mesma revista. Todos os trabalhos foram do tipo empírico, ou seja, baseados em um estudo prático realizado com a comunidade, na maioria dos casos, surda, analisado posteriormente com base nos objetivos propostos.

Psico-USF, Bragança Paulista, v. 18, n. 1, p. 77-88, jan./abril 2013
Embasamento teórico e objetivos dos trabalhos selecionados

A princípio, a maioria dos trabalhos contextualizou a inclusão. De acordo com Guarinello, Berberian, Santana, Massi e Paula (2006), foi após a Declaração de Salamanca (Espanha, 1994) que se definiu que qualquer aluno com dificuldades de escolarização seria um aluno especial, e caberia à escola se adequar às necessidades desse aluno. De acordo com Lacerda (2007),

assim, a opção pela política de inclusão acompanha um movimento mundial e define-se como meta a garantia de que todos os alunos tenham acesso ao ensino regular, confrontando assim as discussões sobre inclusão e educação especial. (p. 260)

A ideia é de que nessa nova proposta de inclusão é a escola quem deve se adequar às necessidades desses alunos, e não o contrário. Os estudos analisados concluíram que apesar de muito ter sido feito no sentido da inclusão, há ainda muita dificuldade para que ela seja realmente efetivada. De acordo com Lacerda (2007):

A fraqueza da inclusão [...] está no fato de que em certo momento, o discurso contradiz a realidade educacional brasileira, caracterizada por classes superlotadas, instalações físicas insuficientes, quadros docentes cuja formação deixa a desejar. Essas condições de existência do sistema educacional levam a questionar a própria idéia de inclusão como política que, simplesmente, insira alunos nos contextos escolares existentes. (p. 261)

Lacerda (2007) afirma que o que tem ocorrido é que, apesar das tentativas de inclusão, a maior parte dos alunos surdos tem uma escolarização pouco responsável. Isso é lamentável, uma vez que esse autor afirma que a inclusão acaba sendo útil para a sociedade em geral, no sentindo de abrir a possibilidade para o contato com as diferenças. Para os surdos, contudo, faltam recursos, tanto físicos, como por exemplo, intérpretes de Libras e materiais adaptados, quanto falta de preparação dos professores e da possibilidade de um plano de ensino específico.

De acordo com Guarinello e cols. (2006), são cerca de seis milhões de crianças e jovens com necessidades educacionais especiais e apenas quatrocentos mil o número de matriculados no ensino regular. Todos os trabalhos selecionados afirmam que um dos principais empecilhos para a 
inclusão é o despreparo dos professores. Seno (2009) também trouxe a questão dos sentimentos dos professores, de insegurança e impotência, ante o fato de saberem que terão de lidar com surdos em sala de aula. Outros ainda citam que há uma disputa entre escola e professores, que jogam de um para o outro a responsabilidade sobre a inclusão. De acordo com Bisol e cols. (2010), "muitos professores não se preocupam em fazer adaptações que favoreçam os alunos surdos, e atribuem o sucesso ou fracasso desses aos serviços de apoio" (p. 152). Mas, no geral, a ideia trabalhada por esses autores é de que são vários os fatores que podem influenciar o processo de inclusão dos surdos. Como afirma Seno (2009):

As barreiras arquitetônicas, o despreparo dos professores, a falta de uma equipe de apoio com profissionais especializados e a resistência dos educadores em modificar as suas práticas são evidentes nesse processo e dificultam ainda mais a acolbida a esses indivíduos. (p. 377)

Com relação aos objetivos dos estudos, pode ser observado que quatro deles focaram principalmente a inclusão sob a ótica dos professores, buscando avaliar os conhecimentos destes sobre os alunos surdos, bem como seus sentimentos e atitudes (Delgado-Pinheiro \& Omote, 2010; Guarinello e cols., 2006; Rios \& Novaes, 2009; Seno, 2009). Rios e Novaes (2009), apesar de mencionarem como sujeito alguns alunos, realizaram a pesquisa toda por meio de entrevistas com os professores. Um dos artigos objetivou analisar uma concepção mais global sobre a efetividade da inclusão no ensino regular, entrevistando o aluno surdo, seus pares, professores e intérpretes (Lacerda, 2007). Outro objetivou investigar a inclusão de jovens surdos no contexto universitário sob a visão dos próprios surdos (Bisol e cols., 2010) E, por fim, um dos estudos teve como objetivo avaliar como uma técnica específica de dramatização pode auxiliar na aprendizagem da escrita por parte do aluno surdo, facilitando sua inclusão nas escolas de ensino regular (Pinotti \& Boscolo, 2008). De modo geral, faltam estudos que investiguem de modo integrado as percepções de alunos (surdos e ouvintes), professores, familiares e profissionais de educação, proporcionando uma compreensão acerca da inclusão baseada em seus diferentes protagonistas.

Metodologias utilizadas nos estudos sobre a inclusão de surdos

A Tabela 3 sumariza as principais metodologias empregadas nos estudos recuperados $(n=7)$, destacando os locais de coleta de dados.

Tabela 3. Metodologias, instrumentos, sujeitos e locais de coleta de dados dos estudos recuperados ( $\mathrm{n}=7$ )

\begin{tabular}{|c|c|c|c|c|}
\hline $\mathrm{N}^{\mathrm{o}}$ & Método & Instrumentos & Sujeitos & Local \\
\hline 1 & Quantitativo & Questionário & $\begin{array}{l}36 \text { professores do ensino } \\
\text { fundamental e médio }\end{array}$ & $\begin{array}{l}\text { Instituição estadual de } \\
\text { ensino }\end{array}$ \\
\hline 2 & Qualitativo & Entrevista & $\begin{array}{l}1 \text { deficiente auditivo e } 2 \text { alunas } \\
\text { ouvintes da } 5^{\text {a }} \text { série do ensino } \\
\text { fundamental }\end{array}$ & $\begin{array}{l}\text { Instituição privada de } \\
\text { ensino }\end{array}$ \\
\hline 3 & Quantitativo & Questionário & $\begin{array}{l}4 \text { deficientes auditivos do ensino } \\
\text { fundamental }\end{array}$ & Instituição de ensino \\
\hline 4 & Qualitativo & Entrevista & $\begin{array}{l}3 \text { deficientes auditivos e } 3 \\
\text { professoras do ensino } \\
\text { fundamental }\end{array}$ & $\begin{array}{l}\text { Instituição privada de } \\
\text { ensino }\end{array}$ \\
\hline 5 & $\begin{array}{l}\text { Qualitativo } \\
\text { exploratório }\end{array}$ & Questionário & $\begin{array}{l}34 \text { professores do maternal ao } \\
\text { EJA (Educação de Jovens e } \\
\text { Adultos) }\end{array}$ & $\begin{array}{l}\text { Instituição municipal de } \\
\text { ensino }\end{array}$ \\
\hline 6 & Qualitativo & Entrevista & 5 graduandos surdos & $\begin{array}{l}\text { Universidade do Sul do } \\
\text { Brasil }\end{array}$ \\
\hline 7 & Quantitativo & $\begin{array}{l}\text { Escala de Atitudes Sociais em } \\
\text { relação à Inclusão (ELASI) e } \\
\text { questionário }\end{array}$ & 72 professores de $1^{\mathrm{a}}$ a $8^{\mathrm{a}}$ série & Instituição de ensino \\
\hline
\end{tabular}


Apesar de bem próximas, a abordagem qualitativa superou a abordagem quantitativa em números, estando presente em quatro dos artigos. De acordo com Flick (2009), há uma tendência por parte dos pesquisadores de utilizar escalas e questionários como se esses fossem capazes de medir com exatidão as condições e características humanas. A abordagem qualitativa deve ser utilizada quando se busca entender o porquê de um fenômeno, e "que os critérios de escolha pela metodologia qualitativa se deem pelo fascínio em querer entender o querer-dizer dos fenômenos humanos, e não por um horror a números" (Turato, 2005, p. 145). Vemos então que, no caso dos artigos selecionados neste estudo, houve um movimento por parte de alguns autores de buscar entender qualitativamente o fenômeno, permitindo-se escutar as falas e entender os significados que os entrevistados traziam da situação analisada. Isso pode ser um reflexo da opinião dos autores de que as questões relacionadas à inclusão dos deficientes auditivos não podem ser avaliadas de forma puramente objetiva para comparações e que, para se entender toda a ideologia que a permeia, devem-se levar em conta os vários aspectos subjetivos, prevalecendo, assim, as metodologias qualitativas.

Com relação aos instrumentos adotados, prevaleceram os questionários, utilizados em quatro estudos. Em segundo lugar apareceram as entrevistas e, em apenas um caso, foi utilizada uma escala padronizada. Evidenciou-se, nesses estudos, a criação dos instrumentos pelos próprios autores - refletindo em parte o método qualitativo - o que auxilia na focalização daquilo que o autor pretende pesquisar. Entendeu-se, também, que a opção pelo questionário foi tomada para facilitar o agrupamento dos dados, e que o método quantitativo foi utilizado pelos estudos que abarcaram o maior número de sujeitos, o que indica que esse método, de fato, é mais abrangente em quantidade de participantes, mas, por vezes, acaba obtendo dados que servirão mais para uma comparação - dando a ideia de "quantos" dentro de um fenômeno -, não explorando o real significado desse fenômeno para os participantes (Turato, 2005).

No que diz respeito ao número de sujeitos envolvido na pesquisa, vemos que, com exceção de três deles, que apresentaram 34, 36 e 72 sujeitos, os outros trabalhos variaram de três a seis sujeitos apenas. Nos estudos com maior número de sujeitos, estes foram professores de alunos surdos; em dois trabalhos foram alunos surdos, um teve ambos tipos de sujeitos, e apenas um teve, além dos alunos surdos, alunos ouvintes. Para Stinson e Liu (1999, citado por Lacerda, 2007, p. 7) entrevistar alunos ouvintes que participam dos processos de inclusão é uma prática pouco frequente. Poucas são as pesquisas que trazem dados sobre como se sentem estes alunos, que dificuldades encontram e que comentários têm a fazer sobre esta realidade.

Isso reforça a necessidade de que outros estudos tragam à baila as opiniões desses alunos, de modo que eles possam apresentar também uma versão acerca da inclusão, o que naturalmente é negligenciado em boa parte das pesquisas científicas, tanto com crianças com alguma deficiência como em situações de risco psicossocial (Rossetti-Ferreira \& Solon, 2010). Apenas um dos estudos foi realizado no âmbito do ensino superior, o que comprova a afirmação de Bortoleto e cols. (2002), de que a inserção do surdo no ensino superior é uma realidade pouco explorada.

Dos trabalhos realizados em ambiente escolar, dois foram realizados em escolas privadas e outros dois em escolas públicas, apresentando, assim, igual prevalência, o que indica a possibilidade de encontrar alunos surdos em processo de inclusão em ambos ambientes e a representatividade das pesquisas dos dois tipos de realidade social. O último fator analisado, gênero, evidenciou que houve em todos os estudos maior quantidade de participantes do sexo feminino, sendo que em um deles foi explicado ser essa prevalência não-proposital (Pinotti \& Boscolo, 2008). Com relação à prevalência de mulheres, no caso dos professores, entende-se ser essa uma profissão ainda vista como feminina (Diogo \& Coutinho, 2006). Porém, não houve resposta para explicar a prevalência do sexo feminino entre os alunos surdos.

\section{Resultados}

Em acordo com a afirmação de Batista (2009), de que, apesar dos esforços que se veem na direção da inclusão escolar, há ainda muita debilidade nesse processo. Os resultados desta pesquisa mostraram em comum (seis dos sete artigos) que, de fato, a inclusão não é efetivada. Também demostraram que, por vezes, ocorrem falsas inclusões, em que se acredita que só o fato de o aluno deficiente estar no mesmo ambiente físico que outro sem deficiências já é uma inclusão por si. Obviamente que essa modalidade acaba caracterizando-se como perversa, na medida em que não compreende as necessidades dos educandos e das pessoas envolvidas (Scorsolini-Comin \& Amorim, 2010).

Entre os estudos que se restringiram à avaliação dos professores sobre a questão da inclusão, todos confirmaram as discussões presentes na literatura científica, de que o despreparo do professor é o maior inimigo da inclusão dos surdos. Seno (2009), por 
exemplo, afirma que "o despreparo do professor ao receber uma criança com deficiência é um dos fatores mais relevantes na inclusão" (p. 382). Essa autora também encontrou que dentre os sentimentos mais comuns dos professores que lidam com surdos estão: medo, insegurança, ansiedade e angústia, e que o despreparo do professor decorre de falhas em sua formação acadêmica, além de falta de conhecimentos sobre aparelhos auditivos, Libras e não utilizar salas de recursos.

Delgado-Pinheiro e Omote (2010) afirmam que "os professores são ideologicamente favoráveis à inclusão, mas não têm conhecimentos suficientes para operacionalizar a proposta de educação inclusiva" (p. 639). Também apontam a necessidade de se criarem programas de apoio tanto para os surdos, quanto para os professores. Os resultados de Rios e Novaes (2009) vêm contribuir para reafirmar essa posição; elas afirmam que

as professoras foram unânimes em admitir que não vêm sendo suficientemente preparadas para recebê-los, nem durante os cursos de formação nem pela equipe de diretores e coordenadores das instituiçôes educacionais de que fazem parte. (p. 95)

As autoras também afirmam terem encontrado, na prática, muito mais pressupostos de integração do que de inclusão, ou seja, a ideia de que quem deve se adequar é o aluno à escola, e que as atitudes ainda são muito individuais, não havendo uma problematização geral com toda a escola, recaindo a responsabilidade sobre o professor. Também defendem que é preciso adaptar projetos individuais para cada criança. Segundo Guarinello e cols. (2006),

o professor ainda tem uma compreensão reducionista sobre o processo de ensino/ aprendizagem dos surdos. $A$ imagem que o professor faz desse aluno como (in)competente e incapaz de aprender também é um fator que deve ser considerado nessa discussão. (p. 329)

Essas autoras ainda afirmam que a inclusão é mais do que possuir vagas abertas e recursos materiais: ela requer uma escola e uma sociedade inclusivas, que assegurem igualdade de oportunidades a todos os alunos, contando com professores capacitados e compromissados com a educação de todos. (Guarinelo e cols., 2006, p. 329)

Esse último estudo, que objetivou analisar tanto o aluno surdo quanto alguns de seus pares ouvintes, apontou que entre os pares há relação de respeito e amizade, porém, pelo fato de os alunos ouvintes não conhecerem a Libras, as relações acabam sendo muito superficiais. Estes conhecem pouco sobre os colegas e não conseguem ter conversas sobre assuntos mais profundos. Contudo, "O aluno surdo parece se satisfazer com isso, já que não conhece outra realidade de interação com pares" (Lacerda, 2007, p. 277). Guarinelo e cols. (2006) também defendem a importância da presença de uma intérprete em sala de aula, embora entendam que esse fato não é garantia de inclusão.

O único estudo que se ocupou do âmbito do ensino superior não encontrou em seus resultados nada que difira dos outros trabalhos. As universidades também não se encontram preparadas para receber os surdos, o intérprete na sala não garante inclusão e os professores são despreparados para lidar com as questões referentes a esses alunos. Porém, acredita-se que, apesar das dificuldades, o ensino superior possibilita ao surdo mudanças positivas em sua vida, já que permite a realização de atividades que não são mais tão restritas à comunidade surda (Bisol e cols., 2010).

O único estudo que se destinou a avaliar uma técnica específica como forma de inclusão, buscando compreender se a dramatização auxiliava na compreensão de textos por parte dos alunos surdos, chegou ao resultado positivo de que a técnica, por trazer um aspecto mais concreto, auxilia na interpretação dos textos por parte dos alunos surdos, concluindo que essa estratégia pode ser empregada para auxiliar no processo de inclusão de surdos.

A proficiência do aprendizado e compreensão pelos deficientes auditivos advém da ação do fazer $e$ da experiência, pois tendo atividades concretas vinculadas ao contexto, obtêm-se uma melhor compreensão e aprendizado. (Pinotti \& Boscolo, 2008, p. 136)

\section{Considerações finais}

Buscando avaliar como as formas de inclusão de deficientes auditivos tendem a ocorrer exclusivamente na área da educação e compreender as lacunas dos estudos na área, esta pesquisa encontrou que, apesar das leis que regulamentam a educação inclusiva, de o assunto ser amplamente debatido e dos esforços dos envolvidos, essa inclusão ainda não ocorre de maneira eficaz, com uma prática muito diferente do que é proposto na política de inclusão. Foi possível perceber que há variedades nas linhas de pesquisa sobre inclusão de surdos em escolas: ao passo que algumas são mais específicas, focando na visão de apenas alguns dos envolvidos no processo de inclusão ou em uma única estratégia, outras buscaram inovar o contexto e ser mais globais. É possível afirmar que, independente de a pesquisa ser realizada em escolas primárias ou de ensino superior, tanto em particulares quanto em públicas, a situação precária de inclusão não difere, tendo como principal fator desta precariedade o despreparo dos professores para lidar com as necessidades especiais dos surdos. Ainda há um olhar 
muito reducionista sobre o assunto, entendendo que apenas o fato de oferecer vagas e alguns recursos já seja garantia de inclusão. Ainda, afirmar que os professores são despreparados para lidar com a temática pode deslocar o foco dos estudos, culpabilizando esses docentes e não oferecendo formação adequada, discussão esta que passa pela readequação das estruturas curriculares dos cursos de Pedagogia, bem como pela oferta de capacitações regulares e fóruns de discussão com professores, alunos, familiares, membros do poder público e profissionais de saúde.

Após essa análise é possível ver a necessidade de mais estudos na área para explorar outros aspectos, como, por exemplo, a realização de pesquisas que busquem avaliar a opinião e a participação dos pais no processo de inclusão escolar dos filhos surdos, ou avaliar a situação sob o olhar dos pais dos alunos ouvintes e de outros funcionários da escola que não sejam os professores. Também é preciso considerar a limitação do presente estudo no que se refere à sua especificidade. Para que se possa entender mais sobre a inclusão dos surdos em um ambiente escolar, seriam necessários outros estudos que abordassem comparativamente a questão da inclusão em outros contextos, o que poderia ser realizado com a inclusão de estudos publicados em outros países. No entanto, a compreensão do estado da arte da inclusão de surdos em nosso país pode balizar não apenas futuras investigações como revisões nas políticas públicas relacionadas à educação. Se no Brasil observamos uma diversidade de práticas e visões do que é a inclusão, em outros países, inclusive naqueles que iniciaram o processo de inclusão escolar há mais tempo, podemos encontrar não apenas diferentes modelos, mas também estratégias bem-sucedidas e que sirvam de norte para intervenções ainda em delineamento no contexto nacional.

\section{Referências}

Baptista, C. R. (2009). Educação especial e o medo do outro: attento ai segnalatil. Em: C. R. Baptista (Org.). Inclusão e escolarização: múltiplas perspectivas (pp. 1729). Porto Alegre: Mediação.

Bisol, C. A., Valentini, C. B., Simioni, J. L., \& Zanchin, J. (2010). Estudantes surdos no ensino superior: Reflexões sobre a inclusão. Cadernos de Pesquisa, 40(139), 147-172.

Borges, L., Bello, R., Leite, S., \& Araújo, R. P. C. (2002). O deficiente auditivo e o mercado de trabalho. Revista Ciências Médicas Biológicas, 1(1), 99104.

Bortoleto, R. H., Rodrigues, O. M. P. R., \& Palamin, M. E. G. (2002). Inclusão escolar enquanto prática na vida acadêmica de portadores de deficiência auditiva. Revista Espaço Informativo Técnico-Científico do INES 1(19), 45-50.

Brasil (1994). Politica nacional de educação especial. Brasília: Autor.

Brasil (1996). Lei n. 9394/96, de 20 de dezembro de 1996: Estabelece as diretrizes e bases da educação nacional. Brasília: Autor.

Brasil (1998). Parâmetros curriculares nacionais: Adaptaçôes Curriculares. Brasília: Autor.

Carreteiro, T. C. (1999). O sofrimento ético-político como categoria de análise da dialética exclusão/inclusão. Em B. Sawaia (Org.). Artimanha da exclusão: análise psicossocial e ética da desigualdade social (pp. 97-116). Petrópolis, RJ: Vozes

Chammé, S. J. (2002). Corpo e saúde: inclusão e exclusão social. Saúde e Sociedade, 11(2), 3-17.

Creswell, J. W. (2010). Revisão da literatura. Em J. W. Creswell. Projeto de pesquisa (pp. 48-75) (3a ed.). (M. Lopes, Trad.). Porto Alegre: Artmed.

Delgado-Pinheiro, E. M. C., \& Omote, S. (2010). Conhecimentos de professores sobre perda auditiva e suas atitudes frente à inclusão. Revista CEFAC, 12(4), 633-640.

Diogo, M. F., \& Coutinho, M. C. (2006). A dialética da inclusão/exclusão e o trabalho feminino. Interações, 11(21), 121-142.

Duarte, J. L., \& Brazorotto, J. S. (2009). Análise das estratégias utilizadas em um grupo terapêutico pedagógico para auxiliar o desenvolvimento da linguagem escrita em crianças com deficiência auditiva. Revista Brasileira de Educação Especial, 15(3), 471-484.

Flick, U. (2009). Introdução à pesquisa qualitativa. (J. E. Costa, Trad.). Porto Alegre: Artmed.

Foucault, M. (1986). Microfísica do poder. Rio de Janeiro: Graal.

Foucault, M. (2001). Os anormais. São Paulo: Martins Fontes.

Franco, M. (2009). Educação superior bilíngue para surdos: o sentido da política inclusiva como espaço da liberdade: Primeiras aproximações. Revista Brasileira de Educação Especial, 15(1), 15-30.

Gesser, A. (2008). Do patológico ao cultural na surdez: para além de um e de outro ou para uma reflexão crítica dos paradigmas. Trabalhos em Linguística Aplicada, 47(1), 223-239.

Guarinello, A. C., Berberian, A. P., Santana, A. P., Massi, G., \& Paula, M. (2006). A inserção do aluno surdo no ensino regular: visão de um grupo de professores do estado do Paraná. Revista Brasileira de Educação Especial, 12(3), 317-330.

Lacerda, C. B. F. (2007). O que dizem/sentem alunos participantes de uma experiência de inclusão 
escolar com aluno surdo. Revista Brasileira de Educação Especial, 13(2), 257-280.

Manente, M. V., Rodrigues O. M. P. R., \& Palamin, M. E. G. (2007). Deficientes auditivos e escolaridade: fatores diferenciais que possibilitam o acesso ao ensino superior. Revista Brasileira de Educação Especial, 13(1), 27-42.

Margall, S. A. C., Honora, M., \& Carlovich, A. L. A. (2006). A reabilitação do deficiente auditivo visando qualidade de vida e inclusão social. $O$ Mundo da Saúde São Paulo, 30(1), 123-128.

Melo, F. R. L. V., \& Ferreira, C. C. A. (2009). O cuidar do aluno com deficiência física na educação infantil sob a ótica das professoras. Revista Brasileira de Educação Especial, 15(1), 121-140.

Monteiro, A. P. H., \& Manzini, E. J. (2008). Mudanças nas concepções do professor do ensino fundamental em relação à inclusão após a entrada de alunos com deficiência em sua classe. Revista Brasileira de Educação Especial, 14(1), 35-52.

Pinotti, K. J., \& Boscolo, C. C. (2008). A dramatização como estratégia de aprendizagem da linguagem escrita para o deficiente auditivo. Revista Brasileira de Educação Especial, 14(1), 121-140.

Ribeiro, K. (2011). Sexualidade e gênero: estudo das relacõos afetivas de jovens surdas de uma escola municipal de educaşão especial de São Paulo. Tese de Doutorado, Faculdade de Educação da Universidade de São Paulo, São Paulo.

Rios, N. V. F., \& Novaes, B. C. A. C. (2009). O processo de inclusão de crianças com deficiência auditiva na escola regular: vivências de professores. Revista Brasileira de Educação Especial, 15(1), 81-98.

Roriz, T. M. S., Amorim, K. S., \& Rossetti-Ferreira, M. C. (2010). Inclusão social de crianças com paralisia cerebral: óptica dos profissionais de saúde. Estudos de Psicologia (Campinas), 27(3), 329-342.

Roso, A., Strey, M. N., Guareschi, P., \& Bueno, S. M. N. (2002). Cultura e ideologia: a mídia revelando estereótipos raciais de gênero. Psicologia \& Sociedade, 14(2), 74-94.

Rossetti-Ferreira, M. C., \& Solon, L. A. G. (2010). A delicada arte da conversa e da escuta. Em D. C. F. Bernardi (Org.). Cada caso é um caso: a voz das crianças $e$ dos adolescentes em acolbimento institucional (pp. 6173). Brasília: SDH/PR.

Sawaia, B. (1999). O sofrimento ético-político como categoria de análise da dialética exclusão/inclusão.
Em B. Sawaia (Org.). Artimanha da exclusão: análise psicossocial e ética da desigualdade social (pp. 97-116). Petrópolis, RJ: Vozes.

Scorsolini-Comin, F., \& Santos, M. A. (2010). Psicologia Positiva e os instrumentos de avaliação no contexto brasileiro. Psicologia: Reflexão e Crítica, 23(3), 440-448.

Scorsolini-Comin, F., \& Amorim, K. S. (2010). Em meu gesto existe o teu gesto: corporeidade na inclusão de crianças deficientes. Psicologia: Reflexão e Critica, 23(2), 261-269.

Seno, M. P. (2009). A inclusão do aluno com perda auditiva na rede municipal de ensino da cidade de Marília. Revista de Psicopedagogia, 26(81), 376-87.

Souza, P. M. (2011). Identificação e caracterização dos alunos com deficiência, transtornos globais do desenvolvimento e altas habilidades/superdotação, matriculados nas classes comuns do ensino regular, na rede pública estadual, em município do interior paulista. Dissertação de Mestrado, Faculdade de Filosofia, Ciências e Letras de Ribeirão Preto da Universidade de São Paulo, Ribeirão Preto, SP.

Sposati, A. (2002). Prefácio. Em B. B. Sawaia \& M. R. Namura. (Org.). Dialética exclusão/inclusão: reflexões metodológicas e relatos de pesquisas na perspectiva da Psicologia Social Crítica. (pp. 7-13). Taubaté, SP: Cabral Editora Universitária.

Takase, E. M., \& Chun, R. Y. (2010). Comunicação e inclusão de crianças com alterações de linguagem de origem neurológica na perspectiva de pais e educadores. Revista Brasileira de Educação Especial, 16(2), 251-264.

Tanaka, E. D. O., \& Manzini, E. J. (2005). O que os empregadores pensam sobre o trabalho da pessoa com eficiência? Revista Brasileira de Educação Especial, 11(2), 273-294.

Turato, E. R. (2005). Métodos qualitativos e quantitativos na área da saúde: definições, diferenças e seus objetos de pesquisa. Revista de Saúde Pública, 39(3), 507-514.

Zortéa, A. M. (2007). Inclusão na educação infantil: as crianças nos (des)encontros com seus pares. Dissertação de Mestrado, Faculdade de Educação, Universidade Federal do Rio Grande do Sul, Porto Alegre.

Recebido em: 09/02/2012

Reformulado em: 31/01/2013

Aprovado em: 14/02/2013 
Sobre os autores:

Roberta Espote é graduanda do curso de Psicologia da Universidade Federal do Triângulo Mineiro (UFTM).

Conceição Aparecida Serralha é docente do Departamento de Psicologia do Desenvolvimento, da Educação e do Trabalho da Universidade Federal do Triângulo Mineiro (UFTM), psicóloga, mestre e doutora em Psicologia pela Pontifícia Universidade Católica de São Paulo (PUC-SP).

Fabio Scorsolini-Comin é docente do Departamento de Psicologia do Desenvolvimento, da Educação e do Trabalho da Universidade Federal do Triângulo Mineiro (UFTM), psicólogo, mestre e doutorando em Psicologia pela Universidade de São Paulo (USP).

Contato com os autores:

Departamento de Psicologia do Desenvolvimento, da Educação e do Trabalho da Universidade Federal do Triângulo Mineiro - UFTM

Avenida Getúlio Guaritá, 159 - Abadia - CEP 38025-440 - Uberaba/MG, Brasil.

E-mail: scorsolini_usp@yahoo.com.br 
